\title{
La ratification de la charte européenne des langues régionales ou minoritaires : la situation $\mathrm{du}$ hongrois en Roumanie
}

A regionális vagy kisebbségi nyelvek európai kartájának ratifikálása - valódi lépés a kisebbségi nyelvek védelmében?

Ratification of the European Charter for Regional or Minority Languages: Is it a Real Step Towards Protection of Minority Languages?

\section{Hajnal Tünde Katona}

\section{OpenEdition \\ Journals}

Édition électronique

URL : https://journals.openedition.org/efo/587

DOI : 10.4000/efo.587

ISSN : 2275-1947

Éditeur

INALCO

Édition imprimée

Date de publication : 1 décembre 2012

ISBN : 978-2-343-02592-6

ISSN : 0071-2051

Référence électronique

Hajnal Tünde Katona, «La ratification de la charte européenne des langues régionales ou minoritaires : la situation du hongrois en Roumanie », Etudes finno-ougriennes [En ligne], 44 | 2012, mis en ligne le 12 février 2014, consulté le 11 juillet 2021. URL : http://journals.openedition.org/efo/587 ; DOl : https://doi.org/10.4000/efo.587

Ce document a été généré automatiquement le 11 juillet 2021.

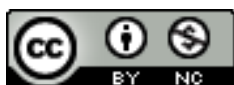

Études finno-ougriennes est mis à disposition selon les termes de la Licence Creative Commons Attribution - Pas d'Utilisation Commerciale 4.0 International. 


\title{
La ratification de la charte européenne des langues régionales ou minoritaires : la situation du hongrois en Roumanie
}

\author{
A regionális vagy kisebbségi nyelvek európai kartájának ratifikálása - valódi \\ lépés a kisebbségi nyelvek védelmében? \\ Ratification of the European Charter for Regional or Minority Languages: Is it a \\ Real Step Towards Protection of Minority Languages?
}

Hajnal Tünde Katona

\section{La minorité hongroise en Roumanie}

1 La langue hongroise est parlée en Transylvanie, car ses locuteurs appartiennent à des groupes ethniques traditionnellement présents dans cette région. Les Hongrois sont devenus involontairement minoritaires au cours de la deuxième décennie du $\mathrm{xx}^{\mathrm{e}}$ siècle, lorsque l'Empire austro-hongrois a été partagé et que ses territoires ont été annexés aux États nouvellement ou récemment formés, comme la Roumanie. Ainsi ${ }^{1}$ les Hongrois se sont-ils retrouvés fragilisés par rapport aux citoyens dont la langue était officiellement devenue celle du nouvel État, la Roumanie. Celle-ci s'était engagée à protéger les minorités ethniques en garantissant l'usage officiel de leurs langues dans tous les domaines de la vie. Le traité de Paris, signé par les représentants de la Roumanie en 1919, fait référence directe au fait qu'aucun citoyen roumain ne peut être entravé dans l'utilisation de sa langue dans la sphère privée, les activités économiques, les réunions religieuses ou publiques, de même que dans la presse ; aucune limitation n'est envisageable dans l'utilisation de la langue maternelle devant la justice. En vertu de ce traité, les communautés minoritaires avaient le droit de créer, en utilisant leurs propres ressources matérielles, des établissements d'enseignement utilisant leur 
langue. L'État s'engageait à allouer une part proportionnelle de son budget aux territoires où le nombre de personnes issues d'une minorité était suffisamment important pour soutenir les établissements scolaires, religieux ou charitables (Gerencsér 2005, p. 229).

2 Toutefois, la minorité hongroise a été progressivement privée de ces droits, et les promesses de l'État roumain n'ont guère été suivies d'effet : ni l'autonomie territoriale ni l'indépendance d'organisation des établissements d'enseignement n'ont été garanties ${ }^{2}$, d'où une émigration massive des Hongrois de Roumanie entre les deux guerres et après la Seconde Guerre mondiale, quand le nord de la Transylvanie, occupé au cours de la guerre par la Hongrie, a été réannexé à la Roumanie.

Bien qu'en 1947 la Roumanie ait signé un nouveau traité protégeant l'usage des langues maternelles dans tous les domaines ${ }^{3}$, ce droit a souffert sous le régime communiste: même l'existence d'établissements d'enseignement en langues minoritaires n'était plus garantie ${ }^{4}$.

4 Bien que la loi sur l'éducation ${ }^{5}$ adoptée en 1978 garantisse aux différentes nationalités la possibilité d'apprendre leur langue maternelle, de même que la langue roumaine, et que le chapitre sur les minorités nationales prévoie la création d'établissements d'enseignement et de groupes dans les classes de langue maternelle, cette loi n'a pas été une garantie suffisante pour maintenir l'éducation en hongrois, car, après son entrée en vigueur, une politique de roumanisation des territoires peuplés par les Hongrois a débuté : d'une part on a commencé à peupler ces régions avec des Roumains issus d'autres régions, d'autre part on a fermé les écoles hongroises pour les remplacer par des classes roumaines. Ce processus a atteint son apogée dans les années 1980, quand les dernières écoles hongroises (à Cluj/Kolozsvár et à Bucarest) ont été dissoutes et que l'enseignement professionnel en langue minoritaire a été aboli (Salat 2008, p. 28-39). En outre, l'éducation en langue minoritaire a souffert de grandes modifications: la géographie et l'histoire de la Roumanie ont été enseignées uniquement en roumain, et les élèves hongrois ont été obligés d'étudier la grammaire et la littérature roumaines avec des manuels conçus pour les élèves roumains. On ne tenait pas compte du fait que le roumain n'était pas leur langue maternelle, et qu'ils auraient pu l'apprendre avec plus de succès en l'étudiant selon les méthodes d'acquisition d'une seconde langue, malgré l'excellente connaissance du roumain de la majorité des élèves.

Ceci explique les efforts déployés après 1989 par les représentants de la communauté hongroise pour la reconquête des droits linguistiques mentionnés ci-dessus. Les revendications des Hongrois de Roumanie ${ }^{6}$ sont basées non seulement sur l'histoire des Hongrois en Transylvanie, c'est-à-dire sur le fait que la Roumanie n'a pas respecté les traités signés, mais également sur le fait que, malgré plusieurs vagues d'émigration, la minorité hongroise constituait toujours la principale minorité de Roumanie. Ainsi, même si nous tenons compte de la dernière vague d'émigration des Hongrois de Transylvanie vers la Hongrie au cours des années 1990, les Hongrois représentaient en 2002 , date du dernier recensement réalisé à ce jour ${ }^{7}, 6,6 \%$ de la population totale de la Roumanie, et environ $25 \%$ de la population de la Transylvanie. En ce qui concerne leur proportion dans les différents départements, on peut dire que les Hongrois représentent la majorité absolue de la population des départements de Harghita (Hargita) et Covasna (Kovászna). Cependant, on trouve dans d'autres départements des endroits où le nombre des Hongrois dépasserait $50 \%$, voire $80 \%$, ce qui est caractéristique de certaines régions de la Transylvanie. 
6 Si on analyse le recensement de 2002, on constate qu'il ne mentionne que le pourcentage de Hongrois par départements. Toutefois celui-ci ne permet pas de déduire la densité des Hongrois dans les communes à l'intérieur d'un département. Sándor Szilágyi N. a montré que la statistique qui tient compte de la concentration de la population dans une zone donnée reflète beaucoup mieux la situation de la population des minorités. Il a calculé le pourcentage dit pondéré des Hongrois dans les départements roumains.

Le pourcentage des Hongrois à l'intérieur d'un département ne permet pas d'atteindre ce but, parce qu'il ne dit rien de la composition ethnique des localités. Il peut arriver que, dans un des départements, il ne vive que relativement peu de Hongrois, et donc que leur pourcentage soit très bas dans ce département, alors même qu'ils forment un bloc compact dans une localité donnée dans laquelle leur pourcentage sera très élevé. Si nous en tenons compte, aussitôt nous apprécierons la situation des Hongrois vivant dans les départements autrement que si nous nous contentons d'examiner la moyenne du département; on constatera parfois même des écarts considérables. Ainsi je ne prendrai pas le rapport numérique du département, mais - si je suis en situation de devoir caractériser un département je tiendrai compte d'un indicateur bien plus approprié, le pourcentage pondéré, que j'ai calculé sur chaque département (d'abord dans son ensemble, puis séparément pour la population urbaine et rurale) en multipliant le nombre de Hongrois vivant dans les localités (et non pas dans les unités administratives) par leur pourcentage correspondant dans la localité, puis en divisant la somme obtenue par le nombre d'habitants. Cet indicateur donne avec une bonne approche une certaine moyenne de la «densité » des Hongrois dans les localités d'un département. (La moyenne arithmétique n'est pas satisfaisante parce que tous les éléments y figurent à poids égal : or, ce n'est pas la même chose si, dans une localité où le pourcentage des Hongrois est de $93 \%$, par exemple, vivent 23500 personnes ou seulement 17 ; de même que le nombre d'habitants n'est pas anodin là où leur proportion est de $9 \%$. Ainsi avec le rapport numérique pondéré, on fait comme si toutes les localités du département dans lesquelles habite au moins un Hongrois, formaient une seule localité dans laquelle le poids des Hongrois est représenté avec le rapport pondéré.) (Szilágyi N. 2005, p. 46).

7 Cette approche permet de modifier de façon substantielle l'appréciation de la situation des Hongrois de Transylvanie, et comme le montre le tableau ci-dessous, les recommandations de la Charte européenne des langues régionales ou minoritaires, que la Roumanie s'est engagée à appliquer, ne doivent pas seulement s'appliquer dans les départements où le recensement montre que le nombre des Hongrois dépasse les $20 \%$, mais aussi, selon la législation en vigueur, dans d'autres départements et localités :

Tableau 1 : Pourcentage et pourcentage pondéré des Hongrois dans les départements de Roumanie (Szilágyi N. 2005, p. 47)

\begin{tabular}{|l|l|l|}
\hline Département & $\begin{array}{l}\text { Pourcentage selon les statistiques de } \\
\text { recensement }\end{array}$ & $\begin{array}{l}\text { Pourcentage } \\
\text { pondéré }\end{array}$ \\
\hline Harghita (Hargita) & 84,72 & 92,22 \\
\hline Covasna (Kovászna) & 75,24 & 86,14 \\
\hline Mureş (Maros) & 41,41 & 61,29 \\
\hline Sălaj (Szilágy) & 23,67 & 60,15 \\
\hline
\end{tabular}




\begin{tabular}{|l|l|l|}
\hline Bihor (Bihar) & 28,44 & 54,37 \\
\hline Satu-Mare (Szatmár) & 35,03 & 54,36 \\
\hline $\begin{array}{l}\text { BistriŢa-Năsăud ( Beszterce- } \\
\text { Naszód) }\end{array}$ & 6,46 & 37,43 \\
\hline Cluj (Kolozs) & 19,85 & 34,57 \\
\hline Alba (Fehér) & 5,98 & 31,52 \\
\hline Arad (Arad) & 12,51 & 30,98 \\
\hline Maramureş (Máramaros) & 10,17 & 26,81 \\
\hline Braşov (Brassó) & 9,88 & 21,33 \\
\hline Timiş (Temes) & 8,98 & 17,69 \\
\hline Hunedoara (Hunyad) & 6,18 & 3,90 \\
\hline Sibiu (Szeben) & 4,26 & 10,72 \\
\hline Caraş-Severin (Krassó-Szörény) & 2,09 & \\
\hline Hors de Transylvanie & 0,14 & \\
\hline
\end{tabular}

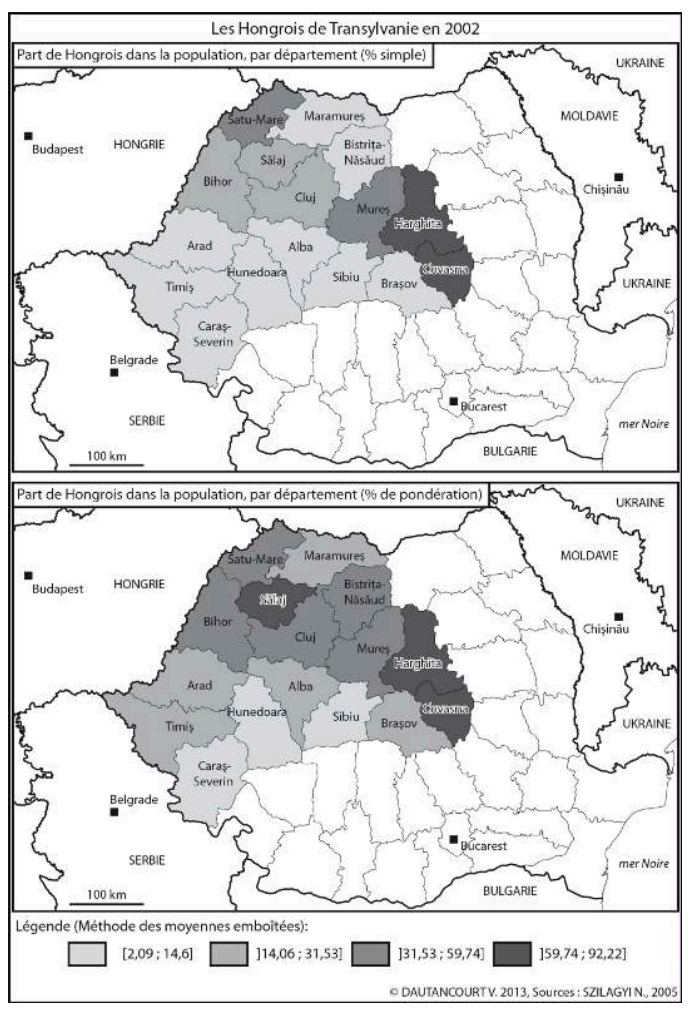




\section{La Charte européenne des langues régionales ou minoritaires et la législation roumaine}

8 La Charte européenne des langues régionales ou minoritaires, rédigée en 1992 par le Conseil de l'Europe, a été un premier pas substantiel pour la protection des minorités dans les pays européens. C'est en fait le premier instrument international par lequel les langues régionales ou minoritaires sont définies d'une manière acceptable pour tous les pays européens. Elle crée par la même occasion une norme minimale en matière de droits linguistiques pour les minorités des pays signataires.

9 La convention de Strasbourg a été signée par la Roumanie en 1995. Ainsi l'État roumain s'est-il engagé à modifier sa législation afin qu'elle reflète la politique de la Charte, c'est-à-dire à mettre en œuvre au moins trente-cinq des recommandations de la III ${ }^{\mathrm{e}}$ partie du document. Bien que signée depuis longtemps, la Charte n'a été ratifiée qu'après l'adhésion de la Roumanie à l'Union européenne en 2007, et la loi de ratification est entrée en vigueur le $1^{\mathrm{er}}$ mai 2008.

10 Au cours des douze années qui se sont écoulées entre la signature de la Charte et sa ratification, la législation roumaine a été modifiée de manière significative, même si la plupart des engagements pris, comme on le verra ci-dessous, ne sont pas inclus dans le cadre législatif actuel.

\section{L'enseignement}

11 La première loi qui reflète les recommandations de la Charte est la loi sur l'éducation ${ }^{8}$ adoptée en 1995. Celle-ci consacre le droit des minorités à étudier dans leur langue à tous les niveaux, pour tous les types et sous toutes les formes d'éducation. Elle réglemente l'étude dans les langues minoritaires des matières de l'enseignement professionnel ${ }^{9}$, ainsi que la création de groupes, départements, écoles, collèges et facultés dans le cadre desquels il sera possible d'organiser l'enseignement en langue minoritaire. La nouveauté de cette loi tient au fait qu'elle prévoit l'introduction d'une nouvelle matière (Istoria şi tradiţiile minorităţilor naţionale - Histoire et traditions des minorités), et qu'elle garantit la rédaction de manuels et d'autres supports didactiques dans la langue maternelle des élèves; elle assure également la représentation proportionnelle des minorités dans l'administration des établissements. Il faut également noter que la loi roumaine prévoit que la géographie et l'histoire soient enseignées exclusivement en roumain à tous les niveaux ; pour ce qui est de la langue et de la littérature roumaines, le fait qu'il ne s'agisse pas de la langue maternelle des élèves est pris en compte dans l'enseignement primaire (seulement les quatre premières classes); mais dès la cinquième classe, les élèves locuteurs d'une langue minoritaire doivent étudier la langue et la littérature roumaines de la même manière que les étudiants roumains. Ainsi les élèves issus d'une minorité ethnique n'ont-ils pas la possibilité d'étudier dans des conditions égales à celles des Roumains. Ce qui précède montre de manière explicite qu'au moment de la ratification de la Charte, la loi sur l'éducation présentait en réalité toutes les dispositions nécessaires et n'avait pas à être modifiée : 
Tableau 2 : La législation en vigueur respecte-t-elle les recommandations de la Charte sur lesquelles la Roumanie s'est engagée?

\begin{tabular}{|l|l|l|l|l|l|l|l|l|l|}
\hline \multicolumn{7}{|l|}{ Paragraphe 1} & \multirow{2}{*}{ Paragraphe 2 } \\
\hline a.i. & b.i. & c.i. & d.i. & e.i. & f.i. & g. & h. & i. & \\
\hline Oui & Oui & Oui & Oui & Oui & Oui & Oui & Oui & Oui & Oui \\
\hline
\end{tabular}

- § 1, a.i. «En matière d'enseignement, les Parties s'engagent [...] à assurer une éducation préscolaire dans les langues régionales ou minoritaires concernées »;

- § 1, b.i. «En matière d'enseignement, les Parties s'engagent [...] à assurer un enseignement primaire dans les langues régionales ou minoritaires concernées »;

- § 1, c.i. « En matière d'enseignement, les Parties s'engagent [...] à assurer un enseignement secondaire dans les langues régionales ou minoritaires concernées »;

- § 1, d.i. « En matière d'enseignement, les Parties s'engagent [...] à assurer un enseignement technique et professionnel dans les langues régionales ou minoritaires concernées »;

- § 1, e.i. « En matière d'enseignement, les Parties s'engagent [...] à assurer un enseignement primaire dans les langues régionales ou minoritaires concernées »;

- § 1, f.i. « En matière d'enseignement, les Parties s'engagent [...] à prendre des dispositions pour que soient donnés des cours d'éducation des adultes ou d'éducation permanente principalement ou totalement dans les langues régionales ou minoritaires »;

- § 1, g. « En matière d'enseignement, les Parties s'engagent [...] à assurer l'enseignement de l'histoire et de la culture dont la langue régionale ou minoritaire est l'expression »;

- § 1, h. « En matière d'enseignement, les Parties s'engagent [...] à assurer la formation initiale et permanente des enseignants nécessaire à la mise en œuvre de ceux des paragraphes a à $g$ acceptés par la Partie »;

- § 1, i. «En matière d'enseignement, les Parties s'engagent [...] à créer un ou plusieurs organe(s) de contrôle chargé(s) de suivre les mesures prises et les progrès réalisés dans l'établissement ou le développement de l'enseignement des langues régionales ou minoritaires, et à établir sur ces points des rapports périodiques qui seront rendus publics»;

- § 2 « En matière d'enseignement et en ce qui concerne les territoires autres que ceux sur lesquels les langues régionales ou minoritaires sont traditionnellement pratiquées, les Parties s'engagent à autoriser, à encourager ou à mettre en place, si le nombre des locuteurs d'une langue régionale ou minoritaire le justifie, un enseignement dans ou de la langue régionale ou minoritaire aux stades appropriés de l'enseignement. »

12 En raison d'un changement du système éducatif roumain en 2011 (soit quatre ans après la ratification de la Charte, et peu de temps après le premier rapport sur sa mise en œuvre), une nouvelle loi sur l'éducation a été adoptée ${ }^{10}$. Celle-ci garantit plus de droits aux minorités que la loi précédente : la grammaire et la littérature roumaines sont enseignées comme celles d'une langue étrangère, garantissant ainsi le droit d'apprendre la langue officielle de l'état de manière efficace. L'article sur la langue d'enseignement de l'histoire et de la géographie de la Roumanie a lui aussi été modifié. La loi permet désormais que ces matières soient enseignées dans les langues minoritaires. Afin de mettre en œuvre ces dispositions, les manuels de géographie et d'histoire ont été récemment traduits du roumain en hongrois et sont utilisés depuis l'année scolaire 2011/2012. Par ailleurs, des experts hongrois (de Roumanie) ont 
élaboré des manuels de géographie et d'histoire, mais leur utilisation dans l'avenir semble incertaine (Krónika 2011, p. 2).

De plus, la nouvelle loi tient compte du fait que, dans les établissements publics d'enseignement en langues minoritaires, le nombre d'élèves est plus faible; ainsi le calcul du budget de ces établissements prévoit un coefficient plus élevé, ce qui permet leur financement.

\section{La justice}

Les lois qui réglementent l'utilisation des langues minoritaires dans les institutions judiciaires (la loi relative aux notaires en droit public et à l'activité notariale, le Code de procédure pénale et le Code de procédure civile) ${ }^{11}$ ont été adoptées entre 1993 et 1997 et reflètent déjà la politique de la Charte. Ainsi les parties peuvent-elles utiliser une langue régionale ou minoritaire sans s'exposer à des coûts supplémentaires, et les preuves verbales ou écrites présentées en langue minoritaire ne sont pas considérées comme nulles pour le seul motif que la langue de rédaction diffère de la langue officielle de l'État: voir les dispositions recommandées par la Charte européenne, paragraphe 9, alinéas a.ii. et a.iii.).

Par la loi portant sur la ratification de la Charte, la Roumanie s'est aussi engagée à mettre en œuvre l'article 9, paragraphe 1 , alinéas c.ii. et c.iii., c'est-à-dire à permettre aux parties de s'exprimer dans leur langue régionale ou minoritaire dans les procédures judiciaires, sans s'exposer à des coûts supplémentaires; cependant, ces dispositions n'ont été incluses dans aucune des lois. Jusqu'à présent, il n'y eut à ce sujet qu'un seul projet de loi sur les procédures administratives, publié en 2008. S'il devait être adopté, conformément au paragraphe 3 de l'article 74, il devrait être possible pour les parties de demander que la procédure se déroule dans leur langue régionale ou minoritaire.

Tableau 3 : La législation respecte-t-elle les recommandations de la Charte sur lesquelles la Roumanie s'est engagée?

\begin{tabular}{|l|l|l|l|l|l|l|l|l|}
\hline \multicolumn{4}{|l|}{ Paragraphe 1} & \multirow{2}{*}{ Paragraphe 2 } & \multirow{2}{*}{ Paragraphe 3 } \\
\hline a.ii. & a.iii. & b.ii. & b.iii. & c.ii. & c.iii. & d. & a. & \\
\hline Oui & Oui & Oui & Oui & Non & Non & Partiellement & Oui & Non \\
\hline
\end{tabular}

- § 1, a.ii. «Les Parties s'engagent [...] dans les procédures pénales [...] à garantir à l'accusé le droit de s'exprimer dans sa langue régionale ou minoritaire »;

- § 1, a.iii. «Les Parties s'engagent [...] dans les procédures pénales [...] à prévoir que les requêtes et les preuves, écrites ou orales, ne soient pas considérées comme irrecevables pour le seul motif qu'elles sont formulées dans une langue régionale ou minoritaire »;

- 1 1, b.ii. «Les Parties s'engagent [...] dans les procédures civiles [...] à permettre, lorsque dans un litige une partie doit comparaître en personne devant un tribunal, qu'elle s'exprime dans sa langue régionale ou minoritaire sans pour autant encourir des frais additionnels »;

- 1 , b.iii. «Les Parties s'engagent [...] dans les procédures civiles [...] à permettre la production de documents et de preuves dans les langues régionales ou minoritaires »; 
- § 1, c.ii. « Les Parties s’engagent [...] dans les procédures devant les juridictions compétentes en matière administrative [...] à permettre, lorsque dans un litige une partie doit comparaître en personne devant un tribunal, qu'elle s'exprime dans sa langue régionale ou minoritaire sans pour autant encourir des frais additionnels »;

- § 1, c.iii. « Les Parties s'engagent [...] dans les procédures devant les juridictions compétentes en matière administrative [...] à permettre la production de documents et de preuves dans les langues régionales ou minoritaires si nécessaire par un recours à des interprètes et à des traductions ";

- 1 1, d. « Les Parties s'engagent [...] à prendre des mesures afin que l'application des alinéas i et iii des paragraphes $b$ et $\mathrm{c}$ ci-dessus et l'emploi éventuel d'interprètes et de traductions n'entraînent pas de frais additionnels pour les intéressés. » ;

- § 2, a. «Les Parties s'engagent à ne pas refuser la validité des actes juridiques établis dans l'État du seul fait qu'ils sont rédigés dans une langue régionale ou minoritaire »;

- § 3 « Les Parties s'engagent à rendre accessibles, dans les langues régionales ou minoritaires, les textes législatifs nationaux les plus importants et ceux qui concernent particulièrement les utilisateurs de ces langues, à moins que ces textes ne soient déjà disponibles autrement. »

\section{Les autorités administratives et les services publics}

16 La nouvelle loi sur l'administration publique et le décret gouvernemental qui réglementent l'utilisation des langues régionales ou minoritaires sont en vigueur depuis 2001 et reflètent également la politique de la Charte.

Ils disposent que :

dans les unités administratives territoriales ${ }^{12}$ où le pourcentage de citoyens relevant des minorités nationales excède $20 \%$ des habitants, les citoyens se voient garantir, dans leurs relations avec les autorités locales, les institutions publiques qui en dépendent et les services publics décentralisés, l'utilisation de leur langue maternelle, conformément à la Constitution, aux dispositions de la présente loi et aux traités internationaux auxquels la Roumanie a souscrit. (Loi $\mathrm{n}^{\circ} 215 / 2001$, art. 19)

17 Ainsi, les personnes issues d'une minorité peuvent s'adresser oralement et/ou par écrit dans leur langue maternelle aux unités territoriales administratives, qui leur répondront en deux langues: dans la langue officielle de l'État et dans celle de la minorité à laquelle elles appartiennent. La loi prévoit que :

les fonctions à responsabilités dans les relations publiques seront aussi occupées par des personnes qui connaissent la langue des citoyens appartenant à la minorité respective. (Loi $\mathrm{n}^{\circ}$ 215/2001, art. 76, alinéa 3)

18 En ce qui concerne l'utilisation des langues régionales ou minoritaires dans les travaux des assemblées locales, la loi établit que l'ordre du jour des réunions est rédigé dans la langue des minorités nationales; la langue minoritaire pourra être utilisée au cours de ces réunions si la population concernée est représentée par au moins un cinquième du nombre total (auquel cas la traduction en roumain sera assurée). L'assemblée locale doit également prononcer les annonces publiques à caractère normatif, ainsi que - à la demande des citoyens - les annonces à caractère individuel, dans la langue de la minorité concernée.

Les autorités locales sont également tenues d'afficher les noms des localités et des établissements publics sous leur autorité dans la langue de la minorité respective. 
Il ressort de ce qui précède que la législation roumaine a déjà couvert la plupart des recommandations de la Charte, mais il serait encore nécessaire de modifier la législation actuelle afin d'éviter un conflit avec la Charte, une fois ratifiée.

Tableau 4 : La législation roumaine régissant les services publics respecte-t-elle les recommandations de la Charte sur lesquelles la Roumanie s'est engagée?

\begin{tabular}{|l|l|l|l|l|l|l|l|l|l|l|l|}
\hline \multicolumn{4}{|c|}{ Paragraphe 1} & \multicolumn{5}{|l|}{ Paragraphe 2} \\
\hline a.ii. & a.iii. & a.iv. & a.v. & b. & c. & b. & c. & d. & e. & f. & g. \\
\hline Oui & Oui & Oui & Oui & Non & Oui & Oui & Oui & Oui & Oui & Oui & Oui \\
\hline
\end{tabular}

\begin{tabular}{|l|l|l|l|l|l|}
\hline \multicolumn{3}{|c|}{ Paragraphe 3 } & \multicolumn{2}{l|}{ Paragraphe 4 } & \multirow{2}{*}{ Paragraphe 5 } \\
\hline a & b & c & b & c & \\
\hline Oui & Oui & Oui & Oui & Oui & Oui \\
\hline
\end{tabular}

\section{Les médias}

21 La protection des langues régionales ou minoritaires et des valeurs des minorités nationales par les médias est assurée par deux lois en vigueur : la loi sur l'organisation et le fonctionnement de la Société roumaine de Radiodiffusion-télévision et de la Société roumaine de Télévision (1994), ainsi que la loi sur l'audiovisuel (2002) ${ }^{13}$. Ces lois stipulent que le Conseil National de l'Audiovisuel (Consiliul NaŢional al Audiovizualului - CNA) a l'obligation d'assurer la protection des cultures et des langues minoritaires par la diffusion d'émissions dans les langues minoritaires; les journalistes doivent s'exprimer correctement, et le temps d'émission est calculé sur la base du pourcentage de la population minoritaire. De la même manière, il est prévu que dans les zones où le pourcentage d'une minorité nationale dépasse $20 \%$, les distributeurs assurent la retransmission de certaines émissions dans la langue de la minorité (cf. Loi n ${ }^{\circ} 504 / 2002$, art. 82). La loi réglemente également la diffusion de certaines productions spécifiques des minorités :

Sur la création européenne diffusée, au moins $30 \%$ seront de création roumaine, comprenant des œuvres spécifiques des minorités. (Loi n ${ }^{\circ} 1 / 1994$, art. 7, alinéa 3)

La protection des valeurs et des langues minoritaires est également assurée : la loi établit le mode de nomination des conseils d'administration des sociétés, étant entendu que l'un des membres est nommé par le groupe parlementaire représentant les minorités ethniques. Il est également stipulé que si les studios de diffusion locale ont des émissions en langues minoritaires, « leurs comités comprendront des représentants des cinéastes de ces émissions » (Loi nº 41/1994, art. 35).

En plus des lois mentionnées plus haut, la protection des valeurs et des langues des minorités nationales est prévue par les décisions du CNA, les décisions ayant un caractère normatif, telle que la décision 403 de 2005 : l'octroi de licences audiovisuelles doit tenir compte 
$\mathrm{du}$ respect du pluralisme politique et social, de la diversité culturelle, linguistique et religieuse [...], de la protection de la culture et de la langue roumaine, des cultures et des langues des minorités nationales. (Décision du CNA, 403/2005, art. 8. alinéa 2)

En ce qui concerne la presse écrite, la loi en vigueur a été adoptée en $1974^{14}$, mais elle est ignorée en raison de la situation actuelle de la presse qui fonctionne sur le principe de l'autorégulation, c'est-à-dire sur le code de conduite édicté par les organisations de journalistes (cf. CRDE / Centrul de Resurse pentru Diversitate Etnoculturală - Centre sur les ressources pour la diversité ethnoculturelle/2009, p. 31).

Tableau 5 : La législation en vigueur respecte-t-elle les recommandations de la Charte sur lesquelles la Roumanie s'est engagée?

\begin{tabular}{|c|c|c|c|c|c|c|c|c|}
\hline \multicolumn{7}{|c|}{ Paragraphe 1} & \multirow{2}{*}{ Paragraphe 2} & \multirow{2}{*}{ Paragraphe 3} \\
\hline a.ii & b.i & c.i & d & e.i & f.i & $\mathrm{g}$ & & \\
\hline Oui & Oui & Oui & Oui & Oui & Oui & Oui & Oui & Oui \\
\hline
\end{tabular}

- § 1, a.ii. « Les Parties s'engagent [...] à encourager et/ou à faciliter la création d'au moins une station de radio et une chaîne de télévision dans les langues régionales ou minoritaires »;

- § 1, b.i. « Les Parties s'engagent [...] à encourager et/ou à faciliter la création d'au moins une station de radio dans les langues régionales ou minoritaires »;

- 1 , c. i. « Les Parties s'engagent [...] à encourager et/ou à faciliter la création d'au moins une chaîne de télévision dans les langues régionales ou minoritaires ";

- 1 , d. « Les Parties s'engagent [...] à encourager et/ou à faciliter la production et la diffusion d'œuvres audio et audiovisuelles dans les langues régionales ou minoritaires »;

- $\S 1$, e.i. «Les Parties s'engagent [...] à encourager et/ou à faciliter la création et/ou le maintien d'au moins un organe de presse dans les langues régionales ou minoritaires »;

- 1 , f.i. «Les Parties s'engagent [...] à couvrir les coûts supplémentaires des médias employant les langues régionales ou minoritaires, lorsque la loi prévoit une assistance financière, en général, pour les médias »;

- 1 , g. «Les Parties s'engagent [...] à soutenir la formation de journalistes et autres personnels pour les médias employant les langues régionales ou minoritaires »;

- § 2 «Les Parties s'engagent à garantir la liberté de réception directe des émissions de radio et de télévision des pays voisins dans une langue pratiquée sous une forme identique ou proche d'une langue régionale ou minoritaire, et à ne pas s'opposer à la retransmission d'émissions de radio et de télévision des pays voisins dans une telle langue. Elles s'engagent en outre à veiller à ce qu'aucune restriction à la liberté d'expression et à la libre circulation de l'information dans une langue pratiquée sous une forme identique ou proche d'une langue régionale ou minoritaire ne soit imposée à la presse écrite. L'exercice des libertés mentionnées ci-dessus, comportant des devoirs et des responsabilités, peut être soumis à certaines formalités, conditions, restrictions ou sanctions prévues par la loi, qui constituent des mesures nécessaires, dans une société démocratique, à la sécurité nationale, à l'intégrité territoriale ou à la sûreté publique, à la défense de l'ordre et à la prévention du crime, à la protection de la santé ou de la morale, à la protection de la réputation ou des droits d'autrui, pour empêcher la divulgation d'informations confidentielles, ou pour garantir l'autorité et l'impartialité du pouvoir judiciaire »; 
- § 3 « Les Parties s'engagent à veiller à ce que les intérêts des locuteurs de langues régionales ou minoritaires soient représentés ou pris en considération dans le cadre des structures éventuellement créées, conformément à la loi, ayant pour tâche de garantir la liberté et la pluralité des médias. »

\section{Activités et équipements culturels}

En matière d'activités et d'équipements culturels (bibliothèques, vidéothèques, centres culturels, musées, archives, académies, théâtres et cinémas, œuvres littéraires, production cinématographique, folklore, festivals, industries culturelles, y compris l'utilisation des nouvelles technologies), la Roumanie s'est engagée à se conformer à toutes les recommandations de la Charte.

Comme cet article touche à plusieurs domaines d'activités et plusieurs types d'équipements culturels, il existe un grand nombre de lois régissant l'utilisation et la protection des langues minoritaires, lois adoptées avant la ratification de la Charte, ou même avant sa signature.

Tableau 6 : La législation en vigueur respecte-t-elle les recommandations de la Charte sur lesquelles la Roumanie s'est engagée?

\begin{tabular}{|l|l|l|}
\hline Paragraphe 1 & Paragraphe 2 & Paragraphe 3 \\
\hline Oui & Oui & Oui \\
\hline
\end{tabular}

- 1 «En matière d'activités et d'équipements culturels - en particulier bibliothèques, vidéothèques, centres culturels, musées, archives, académies, théâtres et cinémas, ainsi que travaux littéraires et de production cinématographique, d'expression culturelle populaire, festivals, industries culturelles, incluant notamment l'utilisation des technologies nouvelles - les Parties s'engagent, en ce qui concerne le territoire sur lequel ces langues sont pratiquées et dans la mesure où les autorités publiques ont une compétence, des pouvoirs ou un rôle dans ce domaine :

a. à encourager l'expression et les initiatives propres aux langues régionales ou minoritaires, et à favoriser les différents moyens d'accès aux œuvres produites dans ces langues ;

b. à favoriser les différents moyens d'accès dans d'autres langues aux œuvres produites dans les langues régionales ou minoritaires, en aidant et en développant les activités de traduction, de doublage, de postsynchronisation et de sous-titrage ;

c. à favoriser l'accès dans des langues régionales ou minoritaires à des œuvres produites dans d'autres langues, en aidant et en développant les activités de traduction, de doublage, de postsynchronisation et de sous-titrage ;

d. à veiller à ce que les organismes chargés d'entreprendre ou de soutenir diverses formes d'activités culturelles intègrent dans une mesure appropriée la connaissance et la pratique des langues et des cultures régionales ou minoritaires dans les opérations dont ils ont l'initiative ou auxquelles ils apportent un soutien ;

e. à favoriser la mise à la disposition des organismes chargés d'entreprendre ou de soutenir des activités culturelles d'un personnel maitrisant la langue régionale ou minoritaire, en plus de la (des) langue(s) du reste de la population ;

f. à favoriser la participation directe, en ce qui concerne les équipements et les programmes d'activités culturelles, de représentants des locuteurs de la langue régionale ou minoritaire ; 
g. à encourager et/ou à faciliter la création d'un ou de plusieurs organismes chargés de collecter, de recevoir en dépôt et de présenter ou publier les œuvres produites dans les langues régionales ou minoritaires ;

h. le cas échéant, à créer et/ou à promouvoir et financer des services de traduction et de recherche terminologique en vue, notamment, de maintenir et de développer dans chaque langue régionale ou minoritaire une terminologie administrative, commerciale, économique, sociale, technologique ou juridique adéquate ";

- § 2 « En ce qui concerne les territoires autres que ceux sur lesquels les langues régionales ou minoritaires sont traditionnellement pratiquées, les Parties s'engagent à autoriser, à encourager et/ou à prévoir, si le nombre des locuteurs d'une langue régionale ou minoritaire le justifie, des activités ou équipements culturels appropriés, conformément au paragraphe précédent »;

- § 3 « Les Parties s'engagent, dans leur politique culturelle à l'étranger, à donner une place appropriée aux langues régionales ou minoritaires et à la culture dont elles sont l'expression.»

\section{Vie économique et sociale}

En ce qui concerne la vie économique et sociale, la Roumanie a surtout veillé à éliminer de la législation toute disposition interdisant ou restreignant indûment l'utilisation des langues régionales ou minoritaires dans les documents relatifs à la vie économique ou sociale, en particulier dans les contrats de travail. Toutefois, la législation comprend cette disposition: "Le contrat de travail individuel est conclu sur la base du consentement des parties, et est rédigé en roumain » (Code du travail, art. 16).

En ce qui concerne les autres engagements, par exemple l'élimination de la législation de toute disposition interdisant ou restreignant indûment l'utilisation des langues régionales ou minoritaires dans les documents techniques (les modes d'emploi de produits ou de machines), dans les règlements intérieurs des entreprises et des documents privés, ou la lutte contre les pratiques tendant à décourager l'usage des langues régionales ou minoritaires dans les activités économiques et sociales, nous pouvons dire qu'aucune loi n'est en contradiction avec les recommandations de la Charte, mais qu'aucune loi n'encourage par ailleurs l'utilisation des langues régionales ou minoritaires.

\section{La Roumanie s'est engagée aussi}

à veiller - dans la mesure où les autorités publiques en ont compétence, dans le territoire sur lequel les langues régionales ou minoritaires sont pratiquées, et dans la mesure où cela est raisonnablement possible - [...] à ce que les équipements sociaux tels que les hôpitaux, les maisons de retraite, les foyers offrent la possibilité de recevoir et de soigner dans leur langue les locuteurs d'une langue régionale ou minoritaire nécessitant des soins pour des raisons de santé, d'âge ou pour d'autres raisons (Charte, art. 13).

30 À cet égard, il existe dans la législation roumaine sur les droits du patient, en particulier dans la loi de 2003, des dispositions énonçant que

si le patient ne parle pas le roumain, les informations lui seront fournies dans sa langue maternelle ou dans une langue qu'il connaît et, le cas échéant, on se tournera vers d'autres formes de communication (Loi $n^{\circ} 43 / 2003$, art. 8).

31 Il faut souligner que la loi évoque seulement la situation dans laquelle les patients ne parlent pas le roumain, mais cette loi ne prévoit pas que le médecin ou le personnel 
médical ait l'obligation de connaître la langue régionale ou minoritaire en question. On ne peut donc pas parler de mise en œuvre de la recommandation de la Charte.

Les deux dernières recommandations sur la vie économique et sociale sont celles qui garantissent le droit à l'information sur la sécurité. Ainsi la Roumanie s'est-elle engagée

à veiller, selon des modalités appropriées, à ce que les consignes de sécurité soient également rédigées dans les langues régionales ou minoritaires [de même qu'à] rendre accessibles dans les langues régionales ou minoritaires les informations fournies par les autorités compétentes concernant les droits des consommateurs (art. 13 de la Charte).

Cependant, la loi sur la protection des consommateurs ${ }^{15}$, bien que modifiée après la ratification de la Charte, ne contient aucune disposition similaire. Les articles 18 et 19, introduits en 2008 par l'ordonnance gouvernementale d'urgence $n^{\circ} 174 / 2008$, ont trait uniquement au droit des consommateurs à être pleinement informés, de façon juste et précise, et à l'obligation d'information sur les produits et services par des éléments d'identification et de caractérisation. La langue des informations est couverte par l'article 20, paragraphe 5. Ainsi, la loi prévoit que

Toutes les informations sur les produits et services offerts aux consommateurs, les documents d'accompagnement, y compris ceux relatifs aux consignes de sécurité $\mathrm{du}$ produit et de son utilisation, ainsi qu'aux contrats, y compris ceux sur formulaire, doivent être rédigés en roumain, indépendamment de leur pays d'origine, sans préjuger de leur présentation dans d'autres langues.

En outre, le paragraphe 7 de cet article, introduit dans la loi après l'ordonnance mentionnée ci-dessus, prévoit que

Les compagnies de transport qui opèrent sur le territoire de la Roumanie sont obligées de fournir aux consommateurs [...] des informations écrites en roumain concernant : l'itinéraire, l'horaire, la durée, la distance, l'espace attribué dans le moyen de transport, les conditions générales de transport et d'autres informations utiles aux consommateurs sur le service en question.

D'après les résultats ci-dessus on peut conclure que sur le plan de la vie économique et sociale au moment de la ratification de la Charte, il n'existait pas de législation en conformité avec la politique de protection des langues régionales ou minoritaires; d'ailleurs, même après l'entrée en vigueur de la loi, aucune mesure n'a été prise pour aller dans le sens des recommandations.

Tableau 7 : La législation en vigueur respecte-t-elle les recommandations de la Charte sur lesquelles la Roumanie s'est engagée?

\begin{tabular}{|l|l|l|l|l|l|l|}
\hline \multicolumn{3}{|l|}{ Paragraphe 1 } & \multicolumn{3}{l|}{ Paragraphe 2 } \\
\hline a & b & c & d & c & d & e \\
\hline Non & Non & Non & Non & Non & Non & Non \\
\hline
\end{tabular}

- 1 , a. « En ce qui concerne les activités économiques et sociales, les Parties s'engagent, pour l'ensemble du pays, à exclure de leur législation toute disposition interdisant ou limitant sans raison justifiable le recours à des langues régionales ou minoritaires dans les documents relatifs à la vie économique ou sociale, et notamment dans les contrats de travail et dans les documents techniques tels que les modes d'emploi de produits ou d'équipements "; 
- 1 , b. « En ce qui concerne les activités économiques et sociales, les Parties s'engagent, pour l'ensemble du pays [...], à interdire l'insertion, dans les règlements internes des entreprises et les actes privés, de clauses excluant ou limitant l'usage des langues régionales ou minoritaires, tout au moins entre les locuteurs de la même langue »;

- § 1, c. «En ce qui concerne les activités économiques et sociales, les Parties s'engagent, pour l'ensemble du pays [...], à s'opposer aux pratiques tendant à décourager l'usage des langues régionales ou minoritaires dans le cadre des activités économiques ou sociales »;

- 1 , d. « En ce qui concerne les activités économiques et sociales, les Parties s'engagent, pour l'ensemble du pays [...], à faciliter et/ou à encourager par d'autres moyens que ceux visés aux alinéas ci-dessus l'usage des langues régionales ou minoritaires »;

- § 2, c. « En matière d'activités économiques et sociales, les Parties s'engagent [...] à veiller à ce que les équipements sociaux tels que les hôpitaux, les maisons de retraite, les foyers offrent la possibilité de recevoir et de soigner dans leur langue les locuteurs d'une langue régionale ou minoritaire nécessitant des soins pour des raisons de santé, d'âge ou pour d'autres raisons. ";

- 2, d. « En matière d'activités économiques et sociales, les Parties s'engagent [...] à veiller, selon des modalités appropriées, à ce que les consignes de sécurité soient également rédigées dans les langues régionales ou minoritaires. »

- § 2, e. «En matière d'activités économiques et sociales, les Parties s'engagent [...] à rendre accessibles dans les langues régionales ou minoritaires les informations fournies par les autorités compétentes concernant les droits des consommateurs. »

\section{Le rapport de la Roumanie sur la mise en œuvre de la Charte européenne} l'éducation n'existait que sous forme de projet de loi, le cadre juridique sur lequel ce rapport s'appuie est la loi précédente, c'est-à-dire celle de 1995, ainsi que ses modifications ultérieures, sans compter un paragraphe de la Constitution qui garantit le droit des minorités à étudier leur langue maternelle et à faire leurs études dans cette langue. 
40 En ce qui concerne les mesures prises pour appliquer la Charte, il existe des données qui reflètent particulièrement la situation et l'organisation du système éducatif roumain des années 1990.

Ainsi est-il mentionné que :

L'éducation en langue minoritaire est organisée en unités indépendantes et en départements, là où, à côté des classes roumaines, il y a des classes hongroises. Tant dans les unités indépendantes que dans les départements, le processus éducatif se déroule dans la langue de la classe. (p. 158)

41 Ce qui n'est pas clairement mentionné dans le présent rapport est le nombre d'unités indépendantes et de départements hongrois existant. En outre, il n'y a aucune référence au fait que dans la plupart des écoles mixtes, les élèves hongrois n'ont pas les mêmes droits que les étudiants roumains puisque ces écoles n'ont par exemple pas de panneaux d'information et de procédures d'inscription en deux langues. La demande des parents de Târgu-Mureş (Marosvásárhely) d'afficher toutes les informations en hongrois en plus du roumain est un exemple récurrent. Un refus y a été opposé à plusieurs reprises (cf. Balogh 2011, Szucher 2011) ${ }^{16}$.

Également sur la base des informations reçues par les étudiants et les professeurs des unités d'enseignement de Cluj (Kolozsvár), il semble que les annonces ne soient pas affichées en hongrois; dans de nombreux cas, les activités parascolaires visant à préserver les traditions de la minorité hongroise se déroulent au niveau des classes, puisqu'elles ne reçoivent pas l'avis favorable de l'administration pour les organiser au niveau de l'école pour tous les élèves ${ }^{17}$.

La présentation générale des mesures prises pour mettre en œuvre les recommandations de la Charte en matière d'éducation se poursuit avec des statistiques sur toutes les formes d'enseignement en langue hongroise, c'est-à-dire des statistiques concernant les étudiants inscrits dans des classes où la langue d'enseignement est le hongrois. Il est évident que le nombre des inscrits ne peut être considéré comme une «mesure" prise par l'État roumain. Les statistiques pourraient refléter de telles mesures seulement si le rapport mettait en évidence l'écart entre le nombre total d'étudiants hongrois inscrits dans les classes hongroises et roumaines avant et après la ratification de la Charte - cet écart pourrait clairement montrer ce qui a été fait pour encourager l'apprentissage de la langue minoritaire.

Le rapport mentionne également le fait qu'« au cours de l'année scolaire 2007-2008, il y avait dix-sept unités et départements d'enseignement professionnel en langue hongroise » (p. 160), ce qui peut être interprété comme une augmentation par rapport aux années précédentes. Puis il indique que le ratio moyen élèves/enseignants dans l'enseignement en hongrois est supérieur au ratio correspondant dans le pays, lequel est plus élevé (dans les écoles maternelles en moyenne 19 enfants par enseignant, dans l'enseignement primaire 19 élèves par enseignant, dans les classes V-XII/XIII 14 élèves par enseignant) que dans l'Union européenne (dans l'enseignement primaire 14 élèves par professeur, dans l'enseignement secondaire 10 élèves par professeur). Même si ce fait peut être démontré statistiquement, il convient de noter qu'en termes de formation professionnelle en langue maternelle, l'éducation est entravée par plusieurs facteurs : premièrement, il n'y a pas de manuels hongrois pour l'étude des matières spécialisées ; deuxièmement, les professeurs qui enseignent ces disciplines ne connaissent pas les termes hongrois spécifiques propres à ces matières; troisièmement, sur la base des informations transmises par des enseignants et des élèves, les matières de base telles 
que les mathématiques ne sont pas enseignées en hongrois. Cette matière est enseignée dans plusieurs écoles professionnelles de Cluj (Kolozsvár) par des enseignants qui ne parlent pas la langue maternelle de leurs élèves alors même que des enseignants hongrois compétents existent ${ }^{18}$.

Le manque d'enseignants parlant le hongrois ne concerne pas seulement les écoles professionnelles, mais également les écoles d'art. À ce sujet, un parent a adressé une lettre aux rédacteurs du site «magyaroktatas.ro » qui décrit en détail le problème des étudiants hongrois à l'École d'art Aurel Pop :

Depuis l'année scolaire 2009, l'enseignement de la théorie de la musique est dispensé par un professeur roumain. Ceci est très troublant puisque, théoriquement, nous avons droit à l'éducation dans notre langue maternelle, mais malheureusement cela n'est pas reconnu par tout le monde. L'année dernière, cette matière a été enseignée en hongrois, mais les enseignants sont à la retraite, et, malheureusement, on n'engage que des enseignants roumains, bien que la moitié des étudiants soit d'origine hongroise (il y a donc deux classes parallèles). Au nom des parents, nous avons déjà présenté une pétition à l'Inspection scolaire du département Satu-Mare (Szatmár), mais rien ne s'est passé comme prévu.

Bien que le phénomène décrit ci-dessus semble être isolé - nous n'avons d'ailleurs pas entrepris d'enquête systématique à cet égard-, il n'en demeure pas moins que le rapport envoyé au Conseil de l'Europe ne peut être considéré comme découlant d'une application de la loi sur l'éducation en Roumanie ; il est donc nécessaire de réexaminer dans son intégralité la mise en œuvre des lois actuelles.

\section{La justice}

En ce qui concerne la mise en œuvre des recommandations de la Charte, le rapport ne fait aucune référence au cadre législatif existant. Ceci montre une absence totale de suivi dans la mise en œuvre de ces recommandations. Deux phrases du rapport permettent d'observer en réalité une généralisation fondée sur des données incertaines :

Il n'existe pas de statistiques sur l'utilisation de la langue hongroise dans des tribunaux, mais par des exemples précis, on sait que cette pratique existe, surtout dans les zones à forte concentration de personnes parlant le hongrois - Covasna (Kovászna), Harghita (Hargita) et Mureş (Maros). Les procès se déroulent en hongrois si les parties impliquées la connaissent, et les procès-verbaux sont rédigés en roumain (p. 174) ${ }^{19}$.

De même que pour l'éducation, il serait nécessaire d'effectuer un suivi systématique pour avoir un aperçu clair de la mise en œuvre des recommandations de la Charte européenne.

\section{Les autorités administratives et les services publics}

49 Le rapport sur les services administratifs et publics ne montre pas davantage à quel niveau se trouve la mise en œuvre de la Charte, parce qu'il ne se réfère ni au cadre juridique ni à des données concrètes. En revanche, il présente une série de déclarations trop générales concernant certains domaines couverts par la loi, sans mentionner les domaines où la loi s'applique uniquement dans quelques localités. En outre, il est évident que ces déclarations ne couvrent pas non plus tous les engagements pris par l'État roumain. 
50 s'explique par l'absence de suivi dans l'application de la Charte. Or une enquête sur l'utilisation des langues régionales ou minoritaires a été réalisée et menée par l'Institut pour l'étude des problèmes des minorités nationales (Institutul pentru Studierea Problemelor Minorităţilor NaŢionale - ISPMN). L'enquête a été réalisée au moyen de questionnaires destinés aux autorités administratives qui, sans exception, les ont remplis et renvoyés à l'Institut.

Sur la base des résultats de cette enquête, on peut affirmer que la communication des citoyens dans leur langue maternelle avec les autorités administratives locales et les services publics existe davantage oralement que par écrit :

Tableau 8 : Utilisation du hongrois dans l'administration et dans les services publics, dans les zones où le pourcentage des citoyens appartenant à la minorité hongroise est supérieur à $20 \%$ (ISPMN, 2009)

\begin{tabular}{|c|c|c|c|c|c|c|c|c|}
\hline \multirow[t]{2}{*}{ Question } & \multicolumn{4}{|c|}{ À l'écrit } & \multicolumn{4}{|c|}{ Oralement } \\
\hline & Oui & Non & $\begin{array}{l}\text { Il n'y a pas } \\
\text { d'institution }\end{array}$ & $\begin{array}{l}\text { Il n'y a } \\
\text { pas de } \\
\text { données }\end{array}$ & Oui & Non & $\begin{array}{l}\text { Il n'y a pas } \\
\text { d'institution }\end{array}$ & $\begin{array}{l}\text { Il n'y a } \\
\text { pas de } \\
\text { données }\end{array}$ \\
\hline $\begin{array}{l}\text { Inscriptions } \\
\text { bilingues dans } \\
\text { la localité }\end{array}$ & $64,5 \%$ & $5,2 \%$ & - & $30,3 \%$ & - & - & - & - \\
\hline $\begin{array}{l}\text { Utilisation de la } \\
\text { langue... à la } \\
\text { mairie } \\
\text { général) }\end{array}$ & $51,7 \%$ & $47,1 \%$ & - & $1,2 \%$ & $95,4 \%$ & $2,8 \%$ & $0 \%$ & $0 \%$ \\
\hline $\begin{array}{l}\text { au bureau de } \\
\text { l'état civil }\end{array}$ & $34,3 \%$ & $60,2 \%$ & $1,2 \%$ & $4,3 \%$ & $82,9 \%$ & $13,8 \%$ & $0,9 \%$ & $2,4 \%$ \\
\hline $\begin{array}{l}\text { au bureau des } \\
\text { permis } \\
\text { commerciaux }\end{array}$ & $19,0 \%$ & $41,6 \%$ & $32,4 \%$ & $7,0 \%$ & $51,4 \%$ & $11,9 \%$ & $30,9 \%$ & $5,8 \%$ \\
\hline $\begin{array}{l}\text { au bureau des } \\
\text { impôts }\end{array}$ & $36,7 \%$ & $58,4 \%$ & $0,9 \%$ & $4,0 \%$ & $87,2 \%$ & $9,8 \%$ & $0,9 \%$ & $2,1 \%$ \\
\hline $\begin{array}{l}\text { au bureau } \\
\text { d'urbanisme }\end{array}$ & $29,4 \%$ & $58,7 \%$ & $8,6 \%$ & $3,4 \%$ & $73,7 \%$ & $14,4 \%$ & $8,3 \%$ & $3,7 \%$ \\
\hline $\begin{array}{l}\text { au bureau } \\
\text { d'aide sociale }\end{array}$ & $36,4 \%$ & $57,8 \%$ & $1,5 \%$ & $4,3 \%$ & $83,8 \%$ & $12,5 \%$ & $1,5 \%$ & $2,1 \%$ \\
\hline à la police & $16,2 \%$ & $76,8 \%$ & $0,3 \%$ & $6,7 \%$ & $55,7 \%$ & $36,1 \%$ & $0 \%$ & $8,3 \%$ \\
\hline à la poste & $25,1 \%$ & $65,7 \%$ & $2,4 \%$ & $6,7 \%$ & $80,4 \%$ & $12,8 \%$ & $1,8 \%$ & $4,9 \%$ \\
\hline
\end{tabular}




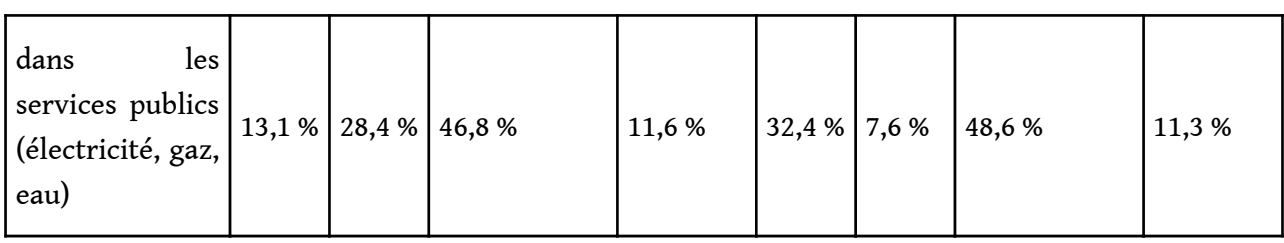

En ce qui concerne la communication avec les résidents appartenant à la minorité hongroise, on observe d'une part que les textes juridiques sont traduits moins fréquemment que les annonces d'intérêt public qui peuvent avoir un caractère privé, et d'autre part que la communication dans la langue maternelle est principalement orale.

Tableau 9 : Utilisation de la langue hongroise dans les conseils locaux où le pourcentage des citoyens appartenant à la minorité hongroise est supérieur à $20 \%$ (ISPMN, 2009)

\begin{tabular}{|l|l|l|l|}
\hline Question & Oui & Non & $\begin{array}{l}\text { Il n'y a pas de } \\
\text { données }\end{array}$ \\
\hline $\begin{array}{l}\text { Est-ce qu'on a rendu public... l'ordre du jour du conseil local dans la } \\
\text { langue de la minorité ? }\end{array}$ & $52,3 \%$ & $45,3 \%$ & $2,4 \%$ \\
\hline $\begin{array}{l}\text {... les décisions réglementaires du conseil local dans la langue de la } \\
\text { minorité ? }\end{array}$ & $38,5 \%$ & $57,8 \%$ & $3,7 \%$ \\
\hline $\begin{array}{l}\text {... les décisions à caractère individuel du conseil municipal dans la } \\
\text { langue de la minorité ? }\end{array}$ & $35,2 \%$ & $59,9 \%$ & $4,9 \%$ \\
\hline$\ldots$ les annonces publiques dans la langue de la minorité ? & $82,3 \%$ & $15,6 \%$ & $2,1 \%$ \\
\hline $\begin{array}{l}\text { Est-ce qu'il y a eu, au cours de la dernière année, des réunions du } \\
\text { conseil municipal au cours desquelles la langue de la minorité a été } \\
\text { utilisée? }\end{array}$ & $63 \%$ & $37 \%$ & $0 \%$ \\
\hline $\begin{array}{l}\text { Y a-t-il des textes ou des formulaires bilingues ou dans la langue } \\
\text { minoritaire à la mairie? }\end{array}$ & $33,6 \%$ & $65,4 \%$ & $0,9 \%$ \\
\hline
\end{tabular}

En analysant les résultats de cette enquête, on ne devrait pas oublier qu'elle montre seulement que la langue hongroise a été utilisée au moins une fois dans les situations présentées ci-dessus; on ne peut donc pas en conclure qu'il s'agit d'une pratique quotidienne. En outre, il faut garder à l'esprit que le sondage a été réalisé au moyen de questionnaires envoyés par la poste, ce qui ne permet pas de vérifier leur exactitude. Ainsi, en tenant compte du fait que les réponses ont pour objectif principal de refléter la ligne officielle de certaines organisations politiques, et non pas des faits, les données ci-dessus peuvent être sujettes à discussion, d'autant qu'il existe déjà d'autres enquêtes dans ce domaine.

En effet celles-ci, comme l'enquête réalisée par exemple par le Mouvement d'engagement civique de Târgu-Mureş (Marosvásárhely) (Civil Elkötelezettség Mozgalom, Civil Engagement Movement, Mişcarea Angajament Civil din Târgu-Mureş CEMO) sont liées à la mise en œuvre de la Charte. Un rapport alternatif, fondé sur une recherche ad hoc, a été soumis au Conseil de l'Europe en mars 2011: des lettres en 
hongrois ont été envoyées aux institutions locales publiques décentralisées dans le département de Mureş (Maros). Cette recherche a conclu à l'existence d'une garantie partielle des droits linguistiques dans le département de Mureş (Maros) :

Sur la base de nos recherches, nous considérons que la communication en langue hongroise avec les autorités administratives et dans les services publics ne fonctionne que partiellement, et uniquement dans certaines institutions (CEMO 2011, p. 34). interdite par le passé dans l'administration, ces termes ont été retirés de la langue parlée et ont été remplacés par des calques ou des mots magyarisés, sans que la Roumanie fasse l'effort de faire connaître aux employés des gouvernements locaux la terminologie appropriée des différents domaines (l'administration publique, la justice, etc.). Ces textes et ces «traductions » sont la preuve que de nombreuses personnes pratiquent un bilinguisme plutôt instable. Cette incertitude qui caractérise la communication en hongrois conduit, dans certains cas, à un phénomène plus grave : dans l'administration, les employés sont dans l'incapacité de s'exprimer correctement dans leur langue maternelle et ne traduisent pas les documents (essentiels ou non), qui ne sont en conséquence affichés qu'en roumain. Il nous suffit de citer l'exemple du village de Sic (Szék) peuplé à 98 \% par des Hongrois, dans lequel la moitié des habitants ne parlent pas roumain. Les autorités locales n'affichent pas les documents en hongrois, ce qui prive la moitié des habitants des informations sur les décisions et les événements majeurs de leur village (Katona 2011).

\section{La vie économique et sociale}

En ce qui concerne la vie économique et sociale de la Roumanie, le rapport rédigé pour le Conseil de l'Europe ne fait aucune référence au cadre législatif applicable et ne contient pas de données pertinentes concernant la mise en œuvre de la Charte européenne des langues régionales ou minoritaires.

Se référant aux points du paragraphe 1 , le rapport est très vague, on peut même dire qu'il déforme la réalité, si l'on considère que la loi prévoit clairement la rédaction des contrats de travail en roumain, ainsi que les modes d'emploi de produits ou de machines, sans préciser l'obligation de les traduire dans une langue minoritaire si cela est nécessaire : 
Il n'existe pas de données sur l'interdiction ou la limitation de l'utilisation du hongrois dans les documents ou les instructions relatives à la vie économique et sociale. Au contraire, la pratique prouve, au moins dans les zones à forte concentration de population hungarophone, que cette langue est utilisée au travail, dans les hôpitaux, les cliniques, les magasins, à la poste, au téléphone et dans divers autres services et activités. Les plus représentatifs sont à cet égard les départements de Covasna (Kovászna) - env. $75 \%$ de la population d'origine hongroise -, Harghita (Hargita) - plus de $80 \%$-, Mureş (Maros) - env. $50 \%$. De nombreux Roms et Roumains dans ces régions parlent le hongrois; il existe donc dans ces régions une tradition de bilinguisme (p. 192).

61 Les faits auxquels le rapport fait référence ne sont pas exceptionnels, dans la mesure notamment où il est inconcevable que deux Hongrois (par exemple un fonctionnaire et un usager) aient une conversation dans une langue autre que le hongrois - ce qui n'est pas énoncé clairement dans ce rapport, puisque d'une part cette situation n'est pas le résultat de mesures étatiques (telles que la formulation explicite des droits linguistiques), et que d'autre part on ne sait pas quelle réalité recouvre l'utilisation du hongrois : est-il parlé parmi les employés des entreprises, hôpitaux, etc. ? Existe-t-il une communication écrite entre employés d'entreprises, d'hôpitaux, etc., et citoyens appartenant à la minorité hongroise ? En outre, ce texte ne fait pas de distinction entre les départements et ne prend pas en compte le fait que dans certains d'entre eux la minorité hongroise dépasse le seuil des $20 \%$, du moins dans certaines localités.

À cet égard, on dispose des données de l'enquête mentionnée ci-dessus, menée par l'Institut pour l'étude des problèmes des minorités nationales.

Tableau 10 : L'utilisation du hongrois dans les institutions sociales où le pourcentage des citoyens appartenant à la minorité hongroise est supérieur à $20 \%$ (ISPMN, 2009)

\begin{tabular}{|l|l|l|l|l|}
\hline Question & Oui & Non & $\begin{array}{l}\text { Il n'y a pas } \\
\text { d'institutions }\end{array}$ & $\begin{array}{l}\text { Il n'y a pas de } \\
\text { données }\end{array}$ \\
\hline $\begin{array}{l}\text { Est-ce qu'il est possible d'utiliser la langue de } \\
\text { la minorité .... à l'hôpital ? }\end{array}$ & $12,5 \%$ & $0 \%$ & $78,3 \%$ & $9,2 \%$ \\
\hline$\ldots$ dans la pratique médicale privée ? & $83,5 \%$ & $8,3 \%$ & $3,7 \%$ & $4,6 \%$ \\
\hline$\ldots$ dans des centres médicaux permanents? & $11,3 \%$ & $0,3 \%$ & $77,4 \%$ & $11,0 \%$ \\
\hline$\ldots$ dans les maisons de retraites? & $11,3 \%$ & $0,6 \%$ & $78,6 \%$ & $9,5 \%$ \\
\hline$\ldots$ dans les orphelinats? & $10,1 \%$ & $0,6 \%$ & $78,3 \%$ & $11,0 \%$ \\
\hline
\end{tabular}

Sur la base de ces données, il apparaît clairement qu'il est possible d'utiliser le hongrois dans la plupart des institutions sociales existantes, mais nous ne possédons aucune information sur les circonstances ou la fréquence de cette utilisation.

En revenant sur le rapport de la Roumanie relatif à la vie économique et sociale, le document mentionne (en se référant aux éléments sélectionnés du paragraphe 2) le fait que l'Autorité nationale pour la protection des consommateurs (Autoritatea NaŢională pentru Protecţia Consumatorilor) ne met pas à leur disposition des formulaires de réclamation en hongrois; mais dans les bureaux régionaux de la protection des 
consommateurs de Covasna (Kovászna), Harghita (Hargita) et Mureş (Maros), les habitants peuvent trouver des formulaires rédigés dans cette langue, et des dépliants d'information y ont été mis à la disposition des consommateurs hongrois. À l'Inspection régionale de la protection des consommateurs de Satu Mare (Szatmár) il y a un employé qui connaît la langue hongroise, et la même institution à Sibiu (Szeben) reçoit des réclamations rédigées en hongrois. Néanmoins - à l'exception des brochures d'information -, tous les cas mentionnés sont soumis à la loi sur le droit administratif, et ne visent pas la mise en œuvre du paragraphe 2 de l'article 13 de la Charte européenne des langues régionales ou minoritaires.

\title{
Conclusions
}

$\mathrm{Au}$ regard de ce qui précède, on pourrait conclure que bien que la législation roumaine couvre la plupart des recommandations de la Charte européenne que la Roumanie a acceptées pour la minorité hongroise, certaines d'entre elles ne sont pas reconnues dans la législation existante, ce qui conduit à une certaine confusion dans l'application des lois. Ainsi, certaines mesures prises pour respecter les droits linguistiques de la Charte ont été attaquées par d'autres organismes publics. Par exemple, l'inscription bilingue de l'hôpital du département à Târnăveni (Dicsőszentmárton), affichée par ordre du Conseil du Département Mureş (Maros), a été déclarée illégale par le Conseil Municipal de Târnăveni, et l'hôpital s'est vu infliger une amende au motif que le pourcentage de Hongrois vivant dans la localité n'est que de $17,74 \%$ : le directeur de l'hôpital n'a donc pas le droit d'afficher le nom de l'institution en langue hongroise (Bodolai 2011).

Il convient également de noter que certains aspects prévus par la charte n'ont pas pu être garantis: ni l'information adéquate des institutions publiques sur les droits garantis par la ratification de la Charte, ni le suivi de l'application des recommandations n'ont été réalisés. Cela conduit à une situation dans laquelle ni les citoyens ni les fonctionnaires ne sont pleinement conscients des droits linguistiques des minorités ; par la même occasion, peu de personnes veulent ou osent s'adresser aux institutions publiques dans leur langue maternelle. De plus, le manque d'information et de suivi conduit d'une part à l'incapacité de produire un rapport qui reflète l'état réel de la situation et d'autre part à une mise en œuvre problématique des recommandations de la Charte par l'État roumain.

Ainsi, on peut conclure que la ratification de la Charte européenne des langues régionales ou minoritaires ne constitue pas un véritable pas en avant dans le processus de protection des langues minoritaires et de confirmation de leurs droits linguistiques.

\section{BIBLIOGRAPHIE}

\author{
Documents officiels
}


*** 1924. Legea învăŢământului primar al statului şi învăţământul normal-primar. Monitorul Oficial nr.161 din 26. iulie 1924, p. 8602-8629.

*** 1947. « ConvenŢia de colaborare culturală între Romănia şi Ungaria. » Adoptée le 25 novembre 1947, à Bucarest. Monitorul Oficial nr. 94 du 21 avril 1948 (ratifiée par la loi no 116/19 avril 1948).

*** 1947. « Tratatul de pace între România şi puterile aliate şi asociate. » Signé le 10 février 1947 à Paris. Monitorul Oficial n 199/30 août 1947 (ratifié par la loi n 304/25 août 1947, promulgué par le décret $n^{\circ} 1786 / 25$ août 1947).

*** 1992. Carta europeană a limbilor regionale sau minoritare.

*** 1992. La Charte européenne des langues régionales ou minoritaires.

*** 2010. Primul raport periodic privind aplicarea Cartei europene a limbilor regionale sau minoritare în România. English version.

*** 1993. Codul de procedură civilă actualizat şi republicat.

*** 1997. Codul de procedură penală actualizat şi republicat.

*** 2001. Legea administraŢiei publice.

*** 2001. HOTĂRÂRE nr. 1.206 din 27 noiembrie 2001 pentru aprobarea Normelor de aplicare a dispoziŢiilor privitoare la dreptul cetăŢenilor aparŢinând unei minorităŢi naŢionale de a folosi limba maternă în administraŢia publica locală, cuprinse în Legea administraŢiei publice locale nr. 215/2001.

*** 2002. Legea audiovizualului.

*** 2003. Legea drepturilor pacientului.

*** 1995. Legea învăŢământului actualizat şi republicat.

*** 1995. Legea notarilor publici și a activităŢii notariale.

*** 1994. Legea privind organizarea şi funcţionarea SocietăŢii Române de Radioteleviziune şi SociertăŢii Române de Televiziune.

*** 2007. Legea privind ratificarea Cartei europene a limbilor regionale sau minoritare.

*** 2003. Legea protecției cumpărătorului actualizată și republicată.

*** 2008. Proiect cod de procedură administrativă.

Institutul pentru Studierea Problemelor MinorităŢilor NaŢionale 2009. Baza de date „Aplicarea legislaŢiei cu privire la drepturile minorităŢilor naŢionale din România”. Cluj-Napoca.

Centrul de Resurse pentru Diversitate Etnoculturală 2009. Monitorizarea implementării Cartei europene a limbilor regionale sau minoritare. (Rapport réalisé dans le cadre du projet „Monitorizarea implementării Cartei europene a limbilor minoritare sau regionale” - « La surveillance de mis en œuvre de la Charte européenne des langues régionales ou minoritaires »)

Civil Elkötelezettség Mozgalom 2011. Shadow Report to the Initial Periodical Report on the Implementation of the European Charter for Regional or Minority Languages in Romania. TârguMureş.

Consiliul NaŢional pentru Combaterea Discriminării 2011. Hotărârea nr. 172 din data de 04.05.2011. [Petent: AsociaŢia Mișcarea Angajament Civic. Reclamat: Gimnaziul Europa, Gimnaziul "Liviu Rebreanu, Gimnaziul “Dacia”, şcoala Generală nr. 2 - Târgu Mureş, Inspectoratul şcolar JudeŢean Târgu Mureş, Consiliul Local Târgu Mureş, Primăria Târgu Mureş. Obiect: Nerespectarea 
drepturilor lingvistice referitoare la peisajul lingvistic al instituŢiilor de învăţământ, aflate în subordinea administraţiei publice locale.]

Uniunea Democrată a Maghiarilor din România 1991. Romániai Magyar Demokrata Szövetség. Alapszabályzat. Program. Kiadja az RMDSZ Országos Titkársága, Kolozsvár, június 7.

VARGA Gábor (ed.) s.d. A Romániai Magyar Demokrata Szövetség I. Kongresszusa. Kiadta az RMDSZ Bihar megyei szervezete.

\section{Articles}

*** 2011, „Elkészült a földrajz- és történelemtankönyvek magyar fordítása”, Krónika, augusztus 31. BAKK Miklós, 2004, „Az autonómia-tervek két szakasza Erdélyben 1989 után”, Magyar Kisebbség, 1-2., p. 39-60.

BALOGH Erzsébet, 2011, „Akadályozzák a kétnyelvű iskolai feliratok kifüggesztését Marosvásárhelyen", Erdély.ma, április 21. Web: BoDoLAI Gyöngyi 2011, „Patikamérlegen a kétnyelvűség”, Népújság, 3e mai 2011. BoTTONi Stefano, 2008, Sztálin a székelyeknél. A Magyar Autonóm Tartomány története (1952-1960), ProPrint Könyvkiadó, Csíkszereda.

Consiliul NaŢional al Audiovizualului, 2005, Decizia CNA nr. 403.

DiószEGI László, 1990, „A romániai magyarság története 1919-1940”, In Diószegi László, R. Süle Andrea: Hetven év. A romániai magyarság története 1919-1989. Magyarságkutató Intézet, Budapest. p. 11-44.

GERENCSÉR Balázs, 2005, „Nyelvi jogok - törvények (II.). Nemzetközi egyezmények az I. világháborút követően”, Magyar Kisebbség, 2005, 1-2, p. 224-231.

KATONA Hajnal-Tünde, 2011, Hivatali nyelvhasználat a romániai Széken és Körösfőn a regionális vagy kisebbségi nyelvek európai chartájának ratifikálása után. (manuscrit d'un exposé donné au colloque "Multilingualism in Europe - prospect and practices in East-Central Europe", 2526 mars 2011 organisé par l'Institut Linguistique de l'Académie hongroise des Sciences, Budapest).

SZILÁGYI N. Sándor, 2005, „Asszimilációs folyamatok a romániai magyarság körében”, in: Péntek János-Benő Attila, Nyelvi jogi környezet és nyelvhasználat, Anyanyelvápolók Erdélyi Szövetsége, Kolozsvár.

SzUCHER Ervin, 2011, „Késik az iskolák kétnyelvűsítése Marosvásárhelyen”, Krónika, június 21., p. 4.

\section{ANNEXES}

Tableau des équivalences toponymiques

\begin{tabular}{|l|l|}
\hline roumain & hongrois \\
\hline Harghita & Hargita \\
\hline Covasna & Kovászna \\
\hline
\end{tabular}




\begin{tabular}{|c|c|}
\hline Mureş & Maros \\
\hline Sălaj & Szilágy \\
\hline Bihor & Bihar \\
\hline Satu-Mare & Szatmár \\
\hline BistriŢa-Năsăud & Beszterce-Naszód \\
\hline Cluj & Kolozs \\
\hline Alba & Fehér \\
\hline Arad & Arad \\
\hline Maramureş & Máramaros \\
\hline Braşov & Brassó \\
\hline Timiş & Temes \\
\hline Hunedoara & Hunyad \\
\hline Sibiu & Szeben \\
\hline Caraş-Severin & Krassó-Szörény \\
\hline Ciuc & Csík \\
\hline Gheorgheni & Gyergyó \\
\hline Odorheiu Secuiesc & Udvarhely \\
\hline Reghin & Régen \\
\hline Sângeorgiu de Pădure & Erdőszentgyörgy \\
\hline Sfântu Gheorghe & Sepsiszentgyörgy \\
\hline Târgu Mureş & Marosvásárhely \\
\hline Târgu Secuiesc & Kézdivásárhely \\
\hline Topliţa & Maroshéviz \\
\hline Cluj & Kolozsvár \\
\hline Târnăveni & Dicsőszentmárton \\
\hline
\end{tabular}




\section{NOTES}

1. Sur la base du traité signé à Paris le 9 décembre 1919 entre les principales puissances alliées et la Roumanie.

2. On peut mentionner comme exemple de discrimination des Hongrois la loi sur l'éducation (Legea învăţământului primar al Statului) adoptée en 1924 et publiée dans le Monitorul Oficial (Le Journal officiel roumain, $\left.\mathrm{n}^{\circ} 161\right)$ qui disposait: «L'éducation primaire se fait en roumain dans toutes les écoles de l'État» (art. 7.), bien que le même article prévoie que « dans les communes avec population d'une autre langue que roumaine, le ministère de l'Instruction publique (Ministerul Instrucţiunii Publice) établira des écoles primaires dont la langue d'enseignement sera celle des populations en question ». Pour la période de l'entre-deux-guerres, on peut en outre évoquer la fermeture en masse d'écoles hongroises. À titre d'exemple, entre 1932 et 1937, dans le département d'Udvarhely (Odorheui Secuiesc), où la plupart des habitants étaient hongrois, 74 écoles hongroises ont été fermées. Dans le département de Csík (Ciuc), où la population hongroise était également majoritaire, il n'y avait pas d'école publique avec enseignement en langue hongroise (Diószegi 1990, p.24-25). Une autre disposition discriminatoire de cette loi sur l'éducation est l'article $n^{\circ} 8:$ « Les citoyens roumains ayant perdu leur langue maternelle doivent inscrire leurs enfants exclusivement dans les écoles publiques ou privées avec enseignement en langue roumaine». Cet article a été conçu pour créer un fondement légal aux les recherches visant à découvrir les ancêtres roumains des parents qui voudraient inscrire leurs enfants dans les écoles (cf. Diószegi 1990, p.25). La population hongroise a été également privée de ses droits linguistiques par l'absence de lois sur l'éducation en langue maternelle applicables aux autres niveaux d'enseignement (Diószegi 1990, p. 25).

3. Le traité de paix de Paris entre la Roumanie et les puissances alliées et associées, signé le 10 février 1947 à Paris, énonce que «La Roumanie prend toutes les mesures nécessaires pour garantir à toutes les personnes relevant de la juridiction roumaine, indépendamment de leur race, de leur sexe, de leur langue ou de leur religion, la jouissance des droits de l'homme et des libertés fondamentales, y compris la liberté d'expression, la liberté de la presse et de publication, la liberté de culte, la liberté d'opinion politique et de réunion. 2. La Roumanie s'est également engagée à ce que la législation en vigueur n'établisse pas ou n'implique pas dans son contenu ou dans son application la moindre discrimination entre citoyens roumains sur la base de la race, du sexe, de la langue ou de la religion en ce qui concerne leur personne, leurs biens, leurs intérêts commerciaux, professionnels ou civils, ou en toute autre matière » (art. 3). La Convention sur la coopération culturelle entre la Roumanie et la Hongrie, signée le 25 novembre à Bucarest, prévoit: «Chaque partie contractante aura la plus grande préoccupation pour toutes les sortes d'institutions culturelles, scientifiques, d'enseignement en langue maternelle, d'enseignement artistique et d'éducation physique pour la population minoritaire, sur la base d'une parfaite égalité des droits des citoyens de chaque État, dans l'esprit de progrès et de consolidation de la démocratie dans les deux pays " (art. 2).

4. Bien que sous la pression des Soviétiques, et plus particulièrement celle de Staline, la Constitution de la Roumanie révisée en 1952 ait prévu l'autonomie administrative et territoriale de la population des districts sicules, dans lesquels l'usage de la langue maternelle était théoriquement garanti dans tous les domaines de la vie, la nécessité de réorganiser administrativement les territoires des districts Ciuc (Csík), Gheorgheni (Gyergyó), Odorheiu Secuiesc (Udvarhely), Reghin (Régen), Sângeorgiu de Pădure (Erdőszentgyörgy), Sfântu Gheorghe (Sepsiszentgyörgy), Târgu Mureş (Marosvásárhely), Târgu Secuiesc (Kézdivásárhely), Topliţa (Maroshéviz) a eu des conséquences encore plus désastreuses sur les Hongrois de Roumanie. L'existence de la Région autonome a été une tentative de centraliser la vie sociale des Hongrois de Roumanie dans cette seule région en y déplaçant les organes de presse et les écoles extérieurs à la Région. Le déplacement de l'université Bolyai de Cluj (Kolozsvár) à Târgu Mureş 
(Marosvásárhely) avait même été envisagé. La population ethniquement et/ou culturellement hongroise en dehors de la Région Autonome a souffert de harcèlement politique. La Région autonome hongroise, qui au fil des ans a pratiquement perdu toute autonomie réelle, a été dissoute en 1960 (Bottoni 2008).

5. Loi sur l'éducation et l'enseignement $\mathrm{n}^{\circ} 28$, du 21 décembre 1978 (Monitorul Oficial $n^{\circ} 113 / 26$ décembre 1978).

6. En 1990, à l'occasion du premier congrès de l'Union démocrate des Hongrois de Roumanie (Romániai Magyar Demokrata Szövetség - RMDSZ; Uniunea Democrată a Maghiarilor din România - UDMR), les exigences suivantes ont été formulées : l'inscription dans la Constitution de droits collectifs ainsi que du droit à la liberté des groupes sociaux et des minorités de toutes sortes, la formation d'un système administratif local permettant la libre utilisation des langues minoritaires dans l'administration et dans la vie publique, l'enseignement de la langue maternelle à tous les niveaux et pour toutes les formes d'éducation, ainsi que l'établissement d'un parlement des minorités. Ces exigences ont été revues ou complétées ultérieurement dans la mesure où les représentants des Hongrois ont considéré que les droits des minorités seraient mieux garantis par le développement d'un réseau d'institutions culturelles indépendantes et par l'élaboration d'une nouvelle loi sur les minorités (Bakk 2004 ; UDMR 1991 ; Varga s.d.).

7. Les données du recensement de 2002 ne reflètent pas nécessairement la proportion réelle des Hongrois en Roumanie aujourd'hui. Toutefois, les données du recensement le plus récent, réalisé à l'automne 2011, ne sont pas encore disponibles.

8. Legea învăŢământului (84/1995).

9. Auparavant, il n'était pas possible de faire des études professionnelles en hongrois.

10. Legea învăŢământului (1/2011).

11. Legea notarilor publici şi a activităŢii materiale (36/1995), Codul deprocedură penală (1997), Codul de procedură civilă (1993).

12. Les localités et les départements doivent être compris parmi les unités territoriales administratives.

13. Legea privind organizarea şi funcţionarea Societăţii Române de Radioteleviziune şi SocietăŢii Române de Televiziune (41/1994), Legea audiovizualului (504/2002).

14. Legea presei (3/1974).

15. Legea cu privire la protecţia consumatorului $(449 / 2003)$.

16. Le refus d'afficher les noms des établissements d'enseignement en hongrois là où fonctionnent des classes hongroises a été expliqué par l'administration de l'école et par l'Inspection départementale de Mureş par le fait que cette tâche revient à la mairie de TârguMureş (Marosvásárhely). En ce qui concerne l'affichage exclusif en roumain des informations d'intérêt public, les positions officielles des directeurs d'écoles sont différentes : le gymnase Liviu Rebreanu a motivé ce refus en avançant que «les informations sont destinées aux parents qui doivent connaître la langue officielle de l'État» (CNCD 2011, p. 7). D'autres institutions ont déclaré avoir affiché les informations dans les deux langues. Une catégorie spéciale inclut les textes transmis par le ministère de l'Éducation, affichés dans toutes les institutions «dans la langue dans laquelle ils ont été transmis " (CNCD 2011, p. 7, 8). Enfin la direction du gymnase Liviu Rebreanu et de l'École Générale ${ }^{\circ} 2$ ont motivé leur refus en prétendant que toute erreur de traduction pourrait donner lieu à des interprétations. (CNCD 2011).

17. Ces informations ont été fournies d'une part au cours de conversations personnelles, d'autre part lors d'une recherche personnelle sur l'utilisation de la langue maternelle dans les écoles de Cluj (Kolozsvár) menée en janvier 2009. Les résultats des recherches n'ont pas été encore publiés. 18. Il n'existe pas de données officielles ou de recherches à cet égard. Ces informations nous ont été communiquées par un professeur qui enseigne dans une école professionnelle de cluj (Kolozsvár), et par de nombreux élèves inscrits dans les classes hongroises de la même institution. 
19. Dans le document anglais du rapport, on peut également lire: "In this field minority languages are less used, but those concerned know the possibility opened by the new regulations. In practice, there are situations of using Hungarian language in the areas with high weight of speakers, over $75-80 \%$ of the local population, as it happens in Covasna and Harghita counties" (p. 80).

\section{RÉSUMÉS}

Cet article a pour but de présenter les problèmes de mise en œuvre de la Charte européenne des langues régionales ou minoritaires en Roumanie dans le cas de la minorité hongroise, et les questions relatives à la garantie de ces droits dans la vie quotidienne, là où l'usage de la langue maternelle est essentiel pour la formation et la préservation de l'identité : l'éducation, la communication avec les autorités administratives, les services publics, ainsi qu'avec les représentants de la santé et de la sécurité publique. Comme la minorité hongroise est la plus importante de Roumanie et qu'elle s'est constituée à la suite de péripéties historiques malheureuses, l'article commence par donner un bref aperçu de la situation. Dans la mesure où l'on peut noter quelques améliorations sur le plan juridique en faveur des Hongrois par rapport à la période communiste, je présente ensuite les amendements au cadre législatif roumain adoptés après la signature de l'acte de Strasbourg. Dans la troisième partie de mon article, j'évoque les lacunes dans la mise en œuvre de la Charte européenne en comparant le rapport envoyé par la Roumanie au Conseil de l'Europe à des données factuelles, ce qui donnera une vision plus réaliste des garanties offertes par ces droits.

Jelen írás a Regionális vagy kisebbségi nyelvek európai kartájának a romániai magyarság esetében történő alkalmazása során felmerülő problémákat mutatja be, főként azokat, melyek az oktatás, a közigazgatás és közszolgálat, az egészségügy és a fogyasztóvédelem területein tapasztalhatók. A romániai magyarságnak a román állam által eredetileg biztosított nyelvi jogaitól való megfosztásának rövid történeti áttekintését követően a dolgozatbemutatja azokat a módosításokat, melyek a román törvénykezésben a strasbourgi okirat aláírásától a Karta ratifikálásáig fokozatosan végbementek. A Karta alkalmazásában megnyilvánuló visszásságokat főként az írás harmadik részében jelzem, a Románia által készített első jelentés, illetve a rendelkezésre álló vagy éppen hiányzó adatok párhuzamos bemutatásán keresztül.

The paper presents the problems that emerged in the course of the application of the European Charter for Regional or Minority Languages in the case of Hungarians in Romania. The problems discussed here are related to education, public administration, the civil service, health care, and consumer protection. Following a brief historical overview of the deprivation of Hungarians in Romania of their language rights, which were originally guaranteed by the Romanian state, the paper presents the modifications introduced in Romanian law during the interval between the signing and the ratification of the Charter. Through the parallel analysis of the first report released by Romania, and the available data (as well as the absence of these), the third part of the study draws attention to the anomalies observed in the application of the Charter. 
INDEX

Index géographique : Roumanie, Transylvanie, Bucarest, Strasbourg, Paris

Index chronologique : XXe siècle (fin), XXIe siècle (début), XXe siècle, XXIe siècle

Mots-clés : Charte européenne, droits des minorités, droits linguistiques

nomsmotscles Hongrois

Keywords : European Chart, minority rights, linguistic rights 